GUCH

Extended Abstract

\title{
Anomalous origin of the left main coronary artery from the right coronary sinus in a 19-year-old patient presenting with cardiac arrest: a case report
}

\author{
QLuka Perčin*, \\ QMaja Strozzi, \\ Darko Anić, \\ Mislav Planinc, \\ Goran Međimurec, \\ QTomislav Tokić, \\ Kristina Marić Bešić
}

University of Zagreb School of Medicine, University Hospital Centre Zagreb, Zagreb, Croatia

RECEIVED:

December 6, 2020

ACCEPTED:

December 18, 2020

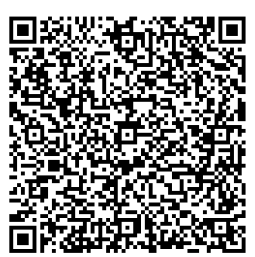

$\square$ Cardiologia Croatica 2021;16(1-2):46.
KEYWORDS: anomalous origin, coronary artery, surgery.

CITATION: Cardiol Croat. 2021;16(1-2):46-7. | https://doi.org/10.15836/ccar2021.46

*ADDRESS FOR CORRESPONDENCE: Luka Perčin, Klinički bolnički centar Zagreb, Kišpatićeva 12, HR-10000 Zagreb, Croatia. / Phone: +385-91-791-7252 / E-mail: luka.percin555@gmail.com

ORCID: Luka Perčin, https://orcid.org/0000-0003-0497-6871 • Maja Strozzi, https://orcid.org/0000-0003-4596-8261 Darko Anić, https://orcid.org/0000-0002-7378-944X • Mislav Planinc, https://orcid.org/0000-0002-9833-832X Goran Međimurec, https://orcid.org/0000-0002-9602-7114 • Tomislav Tokić, https://orcid.org/0000-0001-6871-8746 Kristina Marić Bešić, https://orcid.org/0000-0002-4004-7271

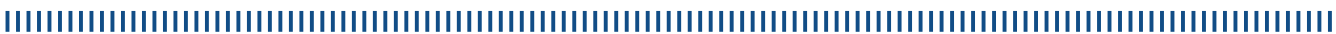

Introduction: An anomalous aortic origin of the left main coronary artery (LMCA) with an inter-arterial or intramural course is a rare but dreadful congenital condition that carries a substantial risk of sudden cardiac death ${ }^{1,2}$. It can present with syncope, myocardial infarction, and arrhythmias that can lead to cardiac arrest. Coronary computed tomography angiography (CCTA) is a commonly used imaging method in detecting the anomaly while cardiac surgery is the treatment of choice ${ }^{3}$.

Case report: We present a case of a 19-year old female with a medical history of intermittent chest pain and presyncope who was hospitalized at the University Hospital Centre Zagreb due to an out of hospital cardiac arrest followed by successful cardiopulmonary resuscitation. At the admission, she was sedated, intubated, mechanically ventilated and hemodynamically stable. After the conduction of an induced hypothermia protocol, the patient was extubated and awakened without signs of neurological deficit. While both echocardiography exam and the magnetic resonance scan confirmed a structurally normal heart, CCTA showed an anomalous origin of the LMCA from the right coronary sinus with an inter-arterial narrow course between the wall of the ascending aorta and pulmonary artery (Figure 1). Since this finding identified the underlying reason for cardiac arrest, the cardiothoracic surgeon was consulted. The patient subsequently underwent cardiac surgery where it was verified that LMCA courses within the anterior aortic wall (Figure 2). A successful „unroofing procedure“ was performed which consisted of an incision of the intramural segment of LMCA with neo-ostium formation at the left

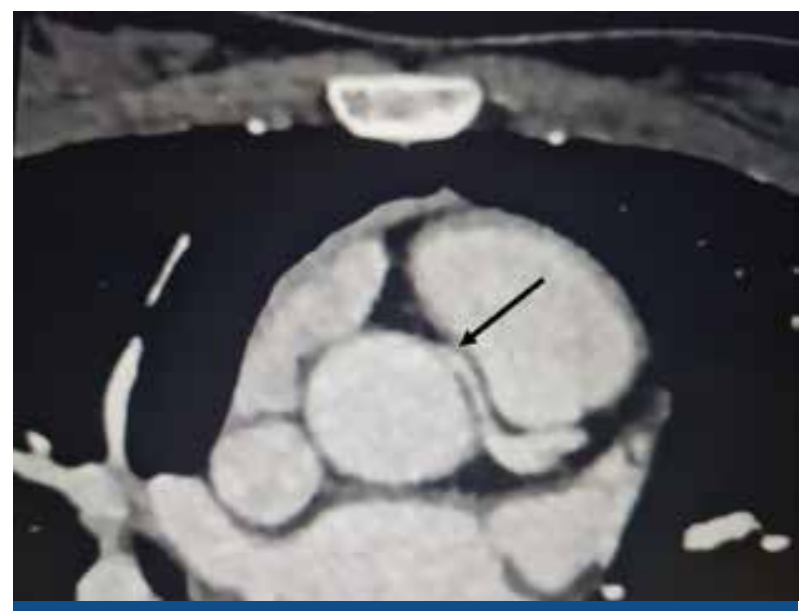

FIGURE 1. Computed tomography coronary angiogram, axial plane. Anomalous origin of left main coronary artery from the right coronary sinus (black arrow).

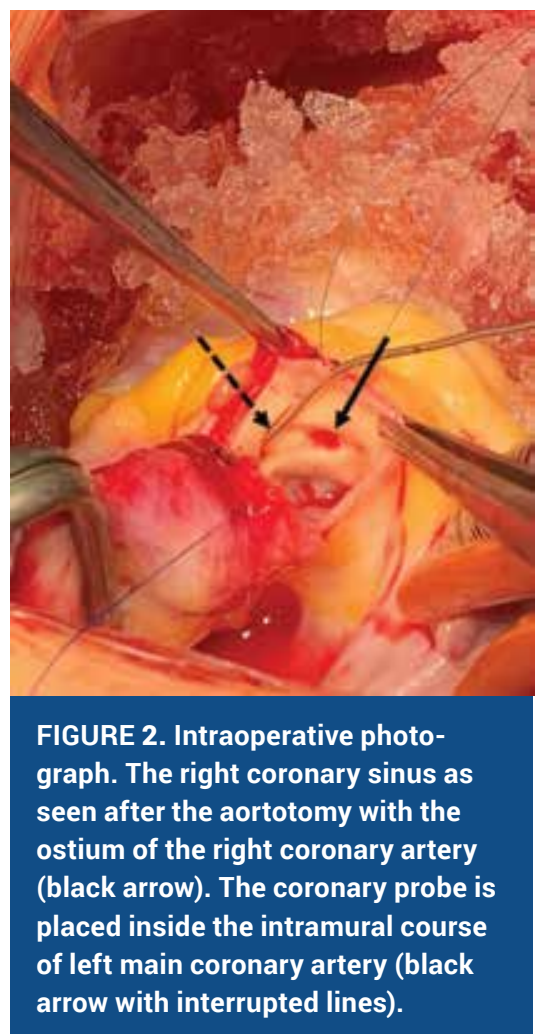



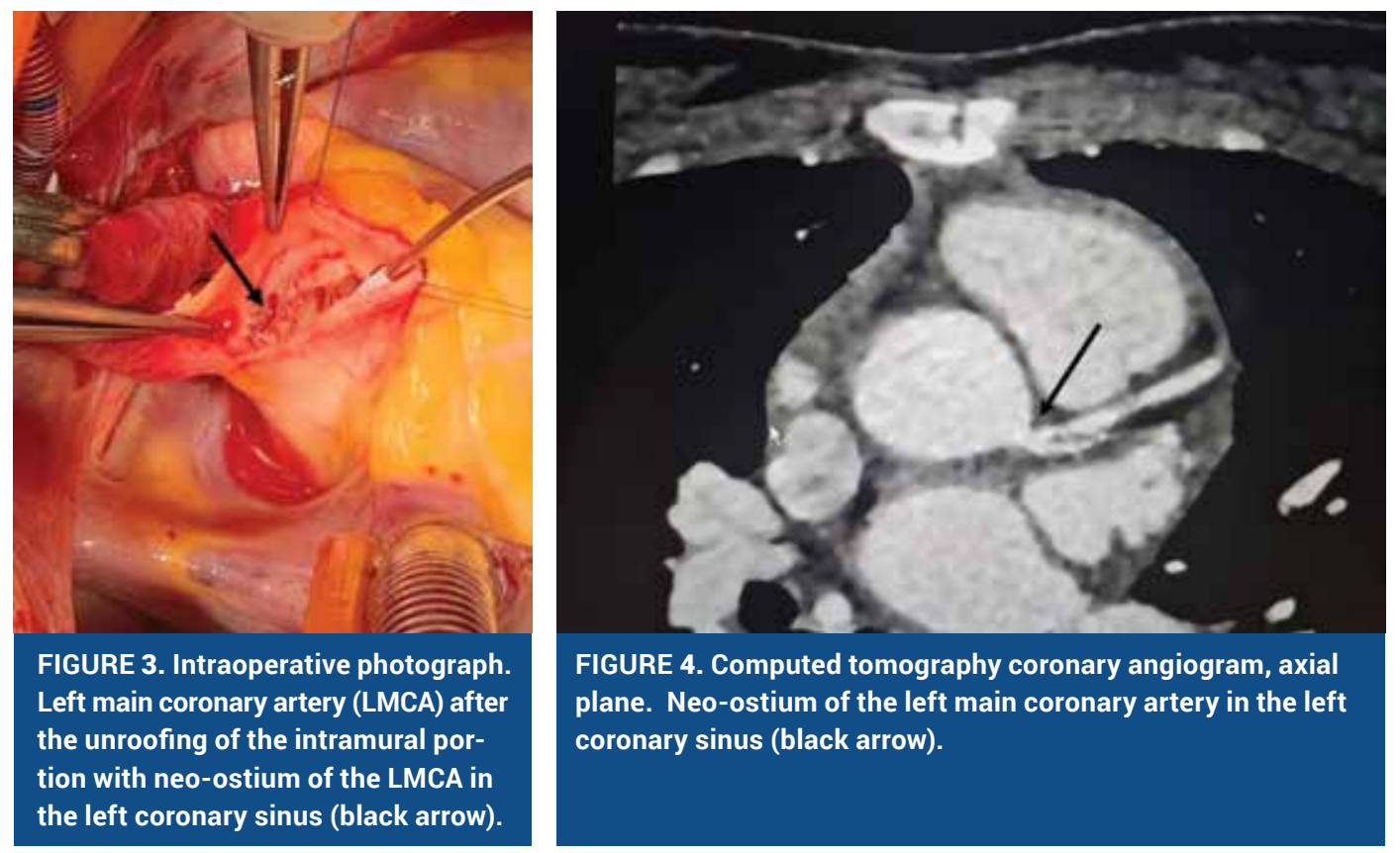

coronary cusp (Figure 3). The patient had an uneventful postoperative period and was discharged without complications. On follow-up, control CCTA confirmed the normal origin and course of LMCA (Figure 4) which correlated with the patient's excellent performance on cardiac exercise stress testing.

Conclusion: The main aim of this case report was to emphasize anomalous LMCA origin as an important cause of chest pain, syncope and arrhythmias that can lead to cardiac arrest in young, otherwise healthy patients. Furthermore, we wanted to point out the „unroofing procedure" as an effective method of anomalous LMCA origin treatment.

1. Khan MS, Idris O, Shah J, Sharma R, Singh H. Anomalous Origin of Left Main Coronary Artery from the Right Sinus of Valsalva: A Case Series-based Review. Cureus. 2020 Apr 22;12(4):e7777. https://doi.org/10.7759/cureus.7777

2. Schubert SA, Kron IL. Surgical Unroofing for Anomalous Aortic Origin of Coronary Arteries. Oper Tech Thorac Cardiovasc Surg. 2016;21(3):162-177. https://doi.org/10.1053/i.optechstcvs.2017.07.001

3. Brothers JA, Frommelt MA, Jaquiss RDB, Myerburg RJ, Fraser CD Jr, Tweddell JS. Expert consensus guidelines: Anomalous aortic origin of a coronary artery. J Thorac Cardiovasc Surg. 2017 Jun;153(6):1440-1457. https://doi.org/10.1016/j.jtcvs.2016.06.066 